\title{
X-linked intellectual disability due to GRIA3 mutations
}

INSERM

\section{Source}

INSERM. (1999). Orphanet: an online rare disease and orphan drug data base. $\underline{X \text {-linked }}$ intellectual disability due to GRIA3 mutations. ORPHA:364028

A rare, genetic, $\mathrm{X}$-linked syndromic intellectual disability disorder characterized by moderate to severe intellectual disability associated with epilepsy, short stature, autistic features and behavioral problems, such as self injury and aggressive outbursts. Observed facial dysmorphism includes brachycephaly, prominent supraorbital ridges, and deep set eyes. Additional variable manifestations include malposition of feet, asthenic habitus, hyporeflexia, bowel occlusions, hydronephrosis, ren arcuatus, delayed motor development and disturbed sleep-wake cycle. 